\title{
Challenges and Opportunities for the Sustainability Transition in Global Trade (introduction)
}

\author{
Valerie Nelsona, Ximena Ruedab, Walter J.V. Vermeulen ${ }^{*}$ \\ a - Natural Resources Institute, University of Greenwich, United Kingdom \\ b - School of Management, Universidad de los Andes, Bogota, Colombia \\ c -Copernicus Institute of Sustainable Development, Utrecht University, Netherlands \\ * - corresponding author
}

In this special issue, we explore the challenges and opportunities arising with respect to normative goals of shifting production and international trade in agriculture towards greater sustainability. Private voluntary sustainability standards have experienced substantial growth in various global markets, reaching $40 \%$ of global coffee production, $25 \%$ of cocoa, and $15 \%$ of palm oil ${ }^{1}$. Given the rapid expansion of private standards, whether third-party certifications, corporate codes of conduct (Vermeulen 2010), or 'newer' regulatory approaches such as multi-stakeholder initiatives, publicprivate partnerships, and efforts to develop new sustainable business models, it is important to consider what such approaches offer. All of these approaches are seeking to contribute, at differing levels of ambition, towards a sustainability transition.

The scope and focus of private standards vary, but in agriculture and forestry the most dominant ones address diverse environmental and social issues and seek increased transparency and traceability in trade. More studies are emerging, but assessing the impact of these voluntary instruments has proven challenging. There are attribution issues (e.g. the construction of robust counterfactual comparisons is not always feasible), plus rigorous impact evaluation is resource and skill-intensive (Nelson and Martin, 2015). Two recent systematic reviews also find that rigorous evidence is lacking and that standards coverage is uneven across commodities and producers, with positive results in only a fraction of the studies, and mixed and inconsistent findings across cases (Oya et al, 2017, DeFries et al. 2017). This reinforces previous research that found mixed outcomes for voluntary standards in different contexts (Alvarez and von Hagen, 2011, 2012; von Hagen and Alvarez 2011, 2012; Potts et al. 2014) including the empirical study by Nelson and Martin, (2012). The global reach of sustainability standards and the diversity of contexts in which they are implemented means outcomes are highly context-specific and makes generalization difficult (Nelson and Martin, 2012; Oyas et al, 2017). Theory-based evaluations can be useful in shedding light on how standards and other sustainability initiatives are expected to work and where strategies can be improved, but more case-comparative analysis is needed to identify success factors. There is already a consensus amongst many actors in the field that complementary programs are needed for scaling (hence the increase in Public-Private Partnerships) due to the limited reach and potentially limited effectiveness of sustainability standards alone (Simons 2014, Molenaar et al. 2015; van Oorschot et al. 2014).

Achieving wider scaling requires action on several fronts. Firstly, standards need to reach more effectively the producers for whom the sustainability transition seems distant and costly, if they are to create true additionality (ITC, EUI, 2016), and not only engage with better off producers who are already compliant with the required best practices (Nelson and Martin, 2013). There are also distributional issues at play: transaction and implementation costs are usually higher for smaller, remotely located farmers than for their wealthier, better-connected counterparts. Efforts are needed to help the most vulnerable producers to shift towards more sustainable practices. More recent innovations could assist in this regard. Firstly, the expansion of direct trade and other forms of alternative trade partnerships that focus primarily in sensorial and physical quality, and create shorter linkages between compliant producers and buyers, thus reducing transaction costs and improving producers' bargaining position, as the supply of these high-quality products is limited to

${ }^{1}$ Global total sales reach $12 \%$ for coffee, $7 \%$ for cocoa, and $8 \%$ for palm oil (IISD, 2014, p. 91). 
specific geographic areas and production and processing methods (Mac Gregor et al. 2017, Rueda et al. 2017). Secondly, these alternative chains and even mainstream markets are showing a growing focus on quality improvement, which potentially could deliver a higher market value for upstream farmers, as they implement better technologies and upgrade.

If standards are to have an impact on ecosystem services, a wider, landscape-scale perspective is necessary in which a larger set of stakeholders is engaged in efforts to reconcile competing land use interests. The voluntary character of standards may give way in such landscape approaches to larger-scale agreements, involving public and private partners that seek to effectively protect ecosystem service provision, by protecting the natural assets that produce the stream of benefits.

However, questions arise as to whether such approaches are in fact more effective in responding to intersecting and growing sustainability challenges, and for whom? Research in this area is expanding. This special issue of Business Strategy and the Environment presents some pioneering research into companies that are looking beyond certification to other kinds of interventions, in which the centrality of sustainability standards associated with third-party certification is not a given. The special issue is the product of the discussions in a dedicated track at the $22^{\text {nd }}$ annual conference of the International Sustainable Development Research Society (ISDRS) in Lisbon in July 2016. The authors attempt to tackle some of the pressing issues regarding the role and effectiveness of standards and these newer initiatives, as private governance mechanisms, exploring their implementation and impacts, and what may be required to achieve sustainability transitions in agriculture and other industries. The research presented covers cases from various parts of the world (Brazil, Burundi, Colombia, Ecuador, West-Africa and Sweden) and addresses various commodities and product categories (coffee, cocoa, cattle, textiles).

The articles contribute to theoretical development through the application and testing of conceptual frameworks, and/or analysis of different strategic approaches. Several articles present new empirical research in sustainable trade to support better understanding of the likely or actual effectiveness of sustainable trade initiatives. Articles include both individual, firm-focused case studies, as well as research on collective and collaborative approaches. The first three articles all explore empirical cases testing the effectiveness of direct trade initiatives. The fourth explores the sustainability transition from a single corporate perspective, identifying and evaluating the potential of adaptive responses to sustainability challenges. The fifth and sixth critically reflect upon the emergent private and hybrid governance arrangements and their political and institutional implications.

The first article (Hernandez-Aguilera et al., 2017) verifies the claim that specialty coffee markets, applying coffee-quality price premiums, can improve business conditions for smallholders and simultaneously promote agro-ecological practices. This claim is empirically tested in a study of 264 smallholders, including a control group, analysing the Relationship Coffee Model (RCM) - a business model that supports long-term partnerships between coffee buyers and smallholders, based on product quality. The results show that RCM participants employed more sustainable resource management practices, have better access to credit and were more informed and optimistic about the coffee business. Based on this the authors suggest a way forward by increasing the close collaboration between value chain partners.

The second article (Rosenberg et al., 2017) addresses the challenges at the bottom of the pyramid in one of the poorest countries in the world, but that also has high potential for direct trade in speciality coffee. Direct trade, focusing on high quality coffee via independent micro-roasters, is found to be a promising approach that pays for material quality improvements and thus has the potential to contribute to poverty reduction, especially in the poorest countries, where marginal impacts on quality can have definitive livelihood benefits. The article considers the case of Burundi, which represents only a minor share of trade within the global coffee market, but where incomes from coffee exports are particularly crucial for rural livelihoods and thus for poverty reduction goals. There is a diversity of production practices in Burundi. Further, the political and institutional context is highly unstable. The article thus argues that to enable Burundian coffee producers to 
capture the possible added value of high-quality coffee, requires a case-specific and space-specific approach, which can best be achieved through transdisciplinary research processes.

The third article (Rueda et al. 2017) also tests the claim that direct trading is an effective means of achieving multiple goals: social, economic and environmental. The article focuses upon direct trade relationships between chocolate makers and cacao farmers in Ecuador. The study presents strong empirical evidence, using socio-economic and biophysical surveys with a sample of 148 farms (including a control group) in three of the largest cacao producing provinces of Ecuador. The study shows that the close collaboration between buyers and the farmers' cooperatives has enabled the latter to capitalize on the qualities of their traditional varieties to access niche markets. Strong cooperatives enable the knowledge held by buyers about what constitutes a high-quality bean to be transferred to farmers. Environmentally, the direct trade model enables the promotion of the conservation of rare cultivars and traditional agroforestry systems, and, from a developmental perspective, also increases incomes. This is made possible by harvesting and processing more specialized, high-quality products and enabling the connection to wealthy urban consumers.

The fourth article (Börjeson and Boström, 2017) focuses on a single firm example, elucidating the global supply chain sustainability challenges in textile production through a case study of a Swedish outdoor company. Applying the concept of reflexive responsibility to analyse the process of sustainable supply chain management it reveals the difficulties a brand-owning company faces, given the balancing acts it must perform to remain viable while proactively seeking to learn and implement upstream responsibility in its supply chains. The case study suggests that even for leading companies that have a public, long-term and process-oriented approach to sustainability, it is necessary to be prepared for unexpected events and to actively identify challenges and possible solutions, by means of open collaboration with supply chain partners. Even with such a proactive approach, companies are still hindered by the lack of a consistent and enabling regulatory environment. The authors call for more intense collaboration between comparable leading brandowning companies given the challenges they share.

The fifth article (Guéneau, 2017) aims to understand the changing role of the state in sustainable cattle supply-chain governance in Brazil in the context of emergent private governance arrangements. The article applies Foucault's work on the notion of neoliberal governmentality to the case of the Brazilian Roundtable on Sustainable Livestock (GTPS), mostly employing a methodology of participant observation. The author analyses the role of the state in such multistakeholder processes, finding it has been influential, particularly in giving Brazilian products greater credibility in international markets. The findings suggest looking beyond the conventional interpretation that demarcates between private and public mechanisms. The author challenges the "paradox of effectiveness": i.e. why many stakeholders continue to support and display a strong propensity for self-organized regulatory instruments, even though strong evidence in the literature suggests that their overall effectiveness is lacking. It calls for the extension of evaluation methods to the political dimension of hybrid forms of governance, including giving attention to changes in the roles and influence of different actors, especially governments, in newly activated networks of private actors.

The sixth article (Nelson and Phillips, 2017) unpacks the theory underpinning farm, sector and landscape-based transformations that are envisaged as resulting from different kinds of sustainability initiatives. It analyses, through a test case of West African cocoa, whether the anticipated theories of change of diverse sustainability initiatives are resilient, transitional or transformational in nature according to current evidence, likely future scenarios and based on political economy understandings. It concludes that current innovations and investment are mostly incremental, often addressing deteriorating baseline conditions (resilience) without enabling smallholders to claim rights and greater representation (transition) or tackling the more fundamental root causes of the vulnerability of smallholders (transformation). The paper discusses the extent to which multi-stakeholder initiatives, Public-Private-Partnerships, sectoral and landscape-based approaches offer routes to scaling. It notes the lack of attention to smallholder and community political empowerment and how multi-stakeholder initiatives can represent an oversight of plural values in rural change processes. A reorientation of stakeholder responses to the 
'cocoa crisis' is needed, particularly from national and local governments: Both productive transformation and institutional changes are needed for territorial economic development. While this is challenging in situations of significant rural governance deficiencies, cocoa industry players are themselves recognizing the imperative for new approaches.

Looking at the wider debate and the research presented in this special issue, we find that there is empirical evidence indicating that direct trade relationships, where there are opportunities for high value markets, can be highly effective in delivering on social, environmental and economic goals. The studies included here empirically test the claims of better quality, better revenues and better social and ecological conditions and each provide meaningful evidence supporting the claims (Hernandez-Aguilera et al., 2017; Rueda et al. 2017). Such schemes involve longer-term partnerships, and avoid the situation which can occur in which standards are (mis-) used as simply the means of avoiding reputational damage by buyers and is motivated by risk avoidance (Vermeulen, 2015). As per Raynolds' work on Fairtrade (Raynolds, 2008), buyers have differing motivations for engaging in trading relationships with smallholder suppliers - these can be 'mission-driven', 'specialty driven', and 'market-driven'. Many buyers fall into the latter category, while direct traders tend to fall into the specialty driven category and/or the mission driven category. There is an inherent tension between fair trade's social goals and the commercial realities of the agrifood business, but with the mainstreaming of fair and ethical trade this has become more of a pertinent issue (Barrientos and Dolan 2006; Bezençon 2011). Where there is a lack of commitment from more mainstream buyers this is likely to filter through in terms of actual buying relationships and the outcomes for smallholder farmers and workers, compared to relational models.

There is growing awareness that individual farm-level standards are not necessarily accessible to certain sections of rural societies and may have limits for some buyers who are seeking increased market differentiation for pioneering activities. Many companies are now looking increasingly to develop and market their own, in-house, own-brand initiatives. Their commitment to third-party sustainability standards may be wavering due to the lack of clear impacts and to company's need to find new ways of boosting their brands, especially when standards become the "new norm" and no longer offer potential for differentiation. However, the question of whether these internal codes of conduct and sustainability standards produce significant progress towards a sustainability transition remains to be seen. Evidence is lacking both for own brand initiatives and for new donor support initiatives which seek to develop new land governance-sustainable business model solutions. This is not to say that such initiatives are not valuable, but it is clear that sustainability issues cannot be addressed at the individual farm-level alone interventions. Wider collaboration and engagement is needed within value chains, with public actors and across landscapes and economies.

As well as the importance of buyer commitment to sustainability, there is an emerging theme relating to the type of adaptive responses needed from companies committed to achieving sustainability. Börjeson and Boström (2017), for example, suggest that proactive learning and responses are needed where companies are operating in complex regulatory and operational environments and that these responses will likely require collaboration with peers. Direct trading relationships require collaborative action along the value chain to facilitate knowledge transfer and exchange and to maximize value addition for different actors, but should be tailored to place and specific value chain. Similarly, the context specificity of production practices and impacts is the current message from evaluative learning on sustainability standards, but more work is needed to evaluate the effectiveness of newer approaches (i.e., sector oriented programs, landscapeapproaches, new sustainable business models, etc.) on the conditions for success in different contexts and greater integration of political and institutional analysis in evaluative research. The latter is particularly important because, learning from experience in the field of sustainability standards, too often assumptions are made about the effectiveness and reach of innovations in sustainable sourcing, about what is needed for success and how to improve practices.

More attention is needed as to how to better align national and sub-regional governance approaches in sustainable trade policies to achieve a more rapid scaling of direct and collaborative supply chain 
initiatives. The latter may have the potential to deliver on political and economic empowerment for smallholders and rural communities, but more research is required. It is important that the community of practice working on sustainability trade, not only considers individual value chain interventions and (what are often) top-down multi-stakeholder initiatives (see Nelson and Phillips, this issue), but it should also ensure that attention is given to how less powerful groups so that they can articulate their visions involving diverse livelihood strategies and pathways and greater influence in rural governance per se. This chimes with the findings of a recent major study by the UN on transformational approaches, including economic development approaches, which concludes that Social and Solidarity Economy (SSE) approaches, such as direct trade, are urgently needed, but currently suffer from fragmentation and limited reach (UNRISD, 2016). The studies in this special issue show strong evidence for how forms of direct and relational trade can deliver positive impact, but they still represent fairly minuscule niche markets linking to a small group of high quality oriented consumers. Scaling direct, relational trade models in other market segments, which carry less promise of premium price levels is a key challenge. Engaging sub-regional governments may be a way to help institutionalize scaling and also ground such value chain models in territorial economic development.

The evidence to date suggests that scaling will require collaboration between broad-based coalitions and networks of entities sharing similar interests and values - where commitment and collaboration is absent, then it is less likely that longer-term partnerships will be created, buying relationships are vulnerable to changes in buyers' business strategies as the quest for market differentiation continues, and corporate laggards and smallholders with fewer assets continue to be unaffected or unable to participate. Sectoral and sector-landscape hybrids offer the potential to achieve greater alignment within industries, and could stimulate systemic change where governments respond and institutionalize requirements for sustainability standards in sourcing. But proving the business case is still necessary and the development case has similarly not yet been established by sector-wide and landscape-approach programmers. Investment is required in demand side measures to stimulate greater demand for high value products, which embrace cultural and environmental values, based upon improved public participation in rural governance and attention to issues of food security and livelihood diversification.

\section{References}

Alvarez, G. \& Hagen, Von, O., 2011. The Impacts of Private Standards on Producers in Developing Countries. Literature Review Series on the Impacts of Private Standards, Part II, Geneva.

Alvarez, G. \& Hagen, Von, O., 2012. When Do Private Standards Work? Literature Review Series on the Impacts of Private Standards; Part IV, Geneva.

Barrientos, S. and C. Dolan (eds) (2006) 'Ethical Sourcing in the Global Food System'. Earthscan. from Routledge.

Bezençon, V., 2011. Producers and the fairtrade distribution systems: what are the benefits and problems? Sustain. Dev. 19, 60-70. doi:10.1002/sd.420

Börjeson, N., M. Boström (2017) Towards reflexive responsibility in a textile supply chain, Business Strategy and the Environment, Vol. 26, Issue x, p. xx

DeFries, R. S., Fanzo, J., Mondal, P., Remans, R., \& Wood, S. A. (2017). Is voluntary certification of tropical agricultural commodities achieving sustainability goals for small-scale producers? A review of the evidence. Environmental Research Letters, 12(3), 033001.

Guéneau, S. (2017) Neoliberalism and the emergence of private sustainability initiatives: the case of the sustainable Brazilian cattle supply chain, Business Strategy and the Environment, Vol. 26, Issue x, p. xx

Hagen, Von, O. \& Alvarez, G., 2011. The Impacts of Private Standards on Global Value Chains. Literature Review Series on the Impacts of Private Standards, Part I, Geneva.

Hagen, Von, O. \& Alvarez, G., 2012. The Interplay of Public and Private Standards: Literature Review Series on the Impacts of Private Standards, Part III, Geneva.

Hernandez-Aguilera, J. N., M.I. Gómez, A.D. Rodewald, X. Rueda, C. Anunu, R. Bennett, H.M. van Es (2017) Quality as a driver of sustainable agricultural value chains: The case of the relationship coffee model, Business Strategy and the Environment, Vol. 26, Issue x, p. xx

ITC, EUI, 2016. Social and Environmental Standards: Contributing to more sustianable value chains. Geneva, Switzerland.

MacGregor MacGregor, F., Ramasar, V., \& Nicholas, K. A. (2017). Problems with Firm-Led Voluntary Sustainability Schemes: The Case of Direct Trade Coffee. Sustainability, 9(4), 651. 
Molenaar, J.W., Gorter, J., Heilbron, L., Simons, L., Vorley, B., Blackmore, E., Dallinger, J., 2015. Sustainable Sector Transformation How to drive sustainability performance in. Amsterdam.

Nelson, V. and A. Martin (2013) 'Assessing the impact of voluntary sustainability standards. NRI report for DFID. Available at:

http://www.nri.org/images/documents/project_websites/AssessingPovertyImpacts/AssessingThePovertyImp actOfSustainabilityStandards.pdf

Nelson, V. and A. Martin (2015) 'Exploring Fairtrade International's multi-dimensional impact in Africa and strategies for improvement'. The Handbook of Fairtrade Research, Edward Elgar

Nelson, V., \& Martin, A. (2012). The impact of Fairtrade: Evidence, shaping factors, and future pathways. Food Chain, 2(1), 42-63.

Nelson, V., D. Phillips (2017) Sector, landscape or rural transformations? Exploring the limits and potential of agricultural sustainability initiatives through a cocoa case study, Business Strategy and the Environment, Vol. 26, Issue $x, p . x x$

Oorschot, M. van, Kok, M., Brons, J., Esch, S. van der, Janse, J., Rood, T., Vixseboxse, E., Wilting, H., Vermeulen, W., 2014. Sustainability of international Dutch supply chains. Progress, effects and perspectives. The Hague.

Oya C, Schaefer F, Skalidou D, McCosker C, Langer L. (2017). Effects of certification schemes for agricultural production on socio-economic outcomes in low-and middle-income countries: a systematic review'. Campbell Systematic Reviews 2017:3. DOI: 10.4073/csr.2017.3

Potts, J., M. Lynch, A., G.A. Huppe, M. Cunningham and V. Voora (2014) The State of Sustainability Initiatives Review 2014: Standards and the Green Economy IISD, 2014

Raynolds, L (2008) 'Mainstreaming Fair Trade Coffee: From Partnership to Traceability'. World Development

Volume 37, Issue 6, June 2009, Pages 1083-1093

Rosenberg, L., M. Swilling, W.J.V. Vermeulen (2017) Practices of Third Wave Coffee: a Burundian producer's perspective, Business Strategy and the Environment, Vol. 26, Issue x, p. xx

Rueda, X., A. Paz, T. Gibbs, R. Leon, B. Moyano and E.F. Lambin (2017) Smallholders at a cross-road: intensify or fall behind? Exploring alternative livelihood strategies in a globalized world, Business Strategy and the Environment, Vol. 26, Issue $x, p . x x$

Simons, L. (2014). Changing the Food Game: Market Transformation Strategies for Sustainable Agriculture. Greenleaf.

UNRISD (2016) 'Promoting Social and Solidarity Economy through Public Policy' Available at: http://www.unrisd.org/80256B42004CCC77/(httpInfoFiles)/7E583F050CE1D2A4C125804F0033363E/\$file/ Flagship2016_Ch4.pdf

Vermeulen, W.J.V., (2010) Sustainable supply chain governance systems: conditions for effective market based governance in global trade. Progress in Industrial Ecology, An International Journal, 7(2), pp.138-162.

Vermeulen, W.J.V., 2015. Self-Governance for Sustainable Global Supply Chains: Can it Deliver the Impacts Needed? Bus. Strateg. Environ. 24, 73-85. doi:10.1002/bse.1804 